\title{
LA CONSTITUCIÓN DE CÁDIZ, LAS ELECCIONES Y LOS MUNICIPIOS
}

\author{
JORGE ANDÚJAR MORENO*
}

\begin{abstract}
Resumen
Este año 2012 se celebran los 200 años -bicentenario- de la Constitución de Cádiz, la primera y única carta política de la monarquía española que consideró como ciudadanos en pie de igualdad a los nacidos en ambos hemisferios. Esto incluía a los criollos, indios y mestizos e inclusive a los analfabetos. Asimismo, el carácter reformista y liberal de la carta gaditana permitió sancionar una serie de libertades y derechos humanos que, con avances y retrocesos, se plasmarían en todas las constituciones peruanas siguientes, de los cuales se yergue como su necesario antecedente y referente. El reconocimiento del pueblo como fuente de soberanía llevó a plasmar las primeras elecciones populares ediles y parlamentarias. Determinó así el surgimiento de la disciplina del Derecho Electoral. Este ensayo resalta en especial la importancia y la histórica autonomía de los municipios, trasplantados al Perú desde España y surgidos desde antes en Roma. Se reflexiona sobre su evolución constitucional y que a pesar de que han sido reconocidas solemnemente por algunas cartas -como la de Cádiz- ello tampoco ha garantizado su fiel cumplimento en los hechos.
\end{abstract}

Palabras clave: Constitución de Cádiz y Municipios - Constitución de Cádiz y Soberanía Popular - Primeras Elecciones Populares - Constitución de Cádiz y Libertades - Constituciones de 1920 y 1933.

\begin{abstract}
This year (2012), we are celebrating the bicentennial of the Constitution of Cadiz, the first and only political chart of the Spanish monarchy that considered those born in both hemispheres as citizens with equal rights, including creoles, indians and mestizos and even the illiterate. Similarly, the reformist and liberal character of the constitution of Cadiz enabled the punishment of a number of human liberties and rights, which would be included in all of the following Peruvian Constitutions, thereby constituting its natural point of reference. The acknowledgement of the peoples as a source of sovereignty led to the first municipal and parliamentary elections, thereby establishing the discipline of Electoral Law. This article highlights the importance and the historical autonomy of the municipalities, transferred from Spain to Peru and which existed long before in Rome, reflecting on its constitutional evolution and on the fact that despite their solemn acknowledgement in some magna cartas - such as the Cadiz Constitution - this has not guaranteed their fulfillment.
\end{abstract}

\footnotetext{
* Profesor de la Universidad Nacional Mayor de San Marcos y de la Universidad Nacional Federico Villarreal.
} 
Jorge Andújar Moreno - La Constitución de Cádiz, las elecciones y los municipios

Key words: Constitution of Cadiz and Municipalities - Constitution of Cadiz and Popular Sovereignty - First Popular Elections - Constitution of Cadiz and Liberties - Constitutions of 1920 and 1933.

\section{Sumario}

1. Primera constitución hispanoamericana. 2. Elecciones de diputados peruanos. 3. Libertades y sufragio. 4. Las primeras elecciones de los alcaldes y de los regidores. 5. Razones del resurgimiento. 6. Las constituciones y la elección popular de los alcaldes. 7. La Constitución de 1920 y las elecciones ediles.

\section{PRIMERA CONSTITUCIÓN HISPANOAMERICANA}

La Constitución de Cádiz -que este año 2012 celebra su bicentenarioes strictu sensu la primera carta del Perú, de España y de muchos países latinoamericanos. La sancionó una constituyente de nítido carácter liberal y partidaria de otorgar amplias libertades. Se promulgó el 19 de marzo de 1812, día de San José, para que rija simultáneamente en todas las "Españas"1, incluyendo en este término no solo a la península, sino a los territorios hispanos situados en América, África y Asia.

El Perú fue uno de los pocos países en donde esta Constitución Política de la Monarquía Española, conocida como "La Pepa" por el día de su promulgación, se juró y rigió. Le cupo tal honor al virrey José de Abascal. Bajo su influjo se comenzó a respirar nuevos aires de libertad, igualdad y se dieron los primeros amagos de elecciones parlamentarias y municipales.

Pudo ser, acaso, la carta política que marque el inicio de la unión en un mismo seno de diversos países hispanoamericanos con estrechos vínculos históricos y retos comunes. El reconocimiento de la igualdad entre peninsulares y criollos y el olvido de las tradicionales políticas coloniales, así lo podía prever. La consolidación, muchas décadas después, de un proyecto semejante por la Comunidad Británica de Naciones (Commonwealth) hace más verosímil esta apreciación.

\section{ELECCIONES DE DIPUTADOS PERUANOS}

Una característica singular de las Cortes, conformada como consecuencia directa de la invasión de la Grande Armée de Napoleón a la península, es

\footnotetext{
1 En la introducción de la Constitución se refiera a Fernando VII como "Rey de las Españas". El Art.5 a "dominio de las Españas", art.10 "territorios de las Españas".
} 
la presencia de al menos nueve diputados peruanos ${ }^{2}$, conjuntamente con representantes de España, México, Cuba, Costa Rica, Nicaragua, Argentina, Chile y Venezuela, entre otros.

Las Cortes estuvieron presididas en un momento por el ilustre abogado, primer constitucionalista del continente, catedrático de San Marcos y efímero Alcalde de Lima don Vicente Morales y Duárez. Se recuerda también a Dionisio Tupac Yupanqui, descendiente directo de los incas, por su discurso en favor de la libertad de los negros ${ }^{3}$ y en especial al fogoso orador y muy popular clérigo trujillano Blas de Ostoloza, acérrimo defensor del rey ${ }^{4}$.

La necesidad de elegir a los diputados provocaron, a partir de agosto de 1809, las primeras elecciones nacionales. Asimismo, en su momento, la dación de las primeras normas legales sobre la materia que hoy se conocen como derecho electoral. El virrey dictaría al efecto un bando por el cual las regulaba y así poder salvar cualquier escollo o impugnación que se presente en el proceso. Conforme a un mandato de la constitución votarían los indígenas por primera vez.

Para estos comicios se empleó un sistema de preselección en dos niveles que partía desde los municipios. ${ }^{5}$ Estos elegirían inicialmente a tres candidatos intachables y por sorteo quedaría sólo uno, cuya balota se presentaría en Lima. Luego el Virrey, a través de otro sorteo, escogería al ganador. Un mecanismo indirecto, aleatorio y aún privilegiado, pero que importaba entonces un avance en el camino de lo que sería tiempo después la conquista del sufragio universal. Bajo este esquema rudimentario 17 municipios en todo el país presentaron sus candidatos.

\section{LIBERTADES Y SUFRAGIO}

El eminente carácter reformista y liberal de la carta gaditana permitió sancionar una serie de libertades y derechos humanos que años después aún bregarían duramente para ser aceptadas. Tuvo, pues, una visión de avanzada que desafortunadamente colisionó violentamente con una sociedad tradicional y absolutista.

\footnotetext{
Ugarte Del PINO, Vicente. Historia de las Constituciones del Perú. Lima: Ed. Andina, 1978, p-29.

3 Ibid., p. 32.

4 TAURO Del Pino, Alberto. Enciclopedia Ilustrada del Perú. Lima: Peisa, 1987, p. 1488. Blas de Ostolaza moriría fusilado en Valencia por su fidelidad al rey.

5 Aljovín de LOSADA; LóPez, Sinesio. Historia de las elecciones en el Perú. Estudios sobre el gobierno representativo. Lima: Ed. EIP, 2005, pp. 27 y ss.
} 
A pesar de su carácter monárquico, influencia de la primera Constitución francesa de 1791, obra del controvertido conde de Mirabeau, reconoció la libertad de pensamiento y de expresión, de imprenta, libertad de comercio, de propiedad, de educación, derecho de petición e inviolabilidad de domicilio, entre otros. Asimismo, dentro de esta línea, dispuso la supresión de las mitas, del tributo indígena y del Tribunal de la Santa Inquisición.

Al establecer como única fuente legítima de soberanía al pueblo, reemplazando la figura de Dios que recogía desde siglos el derecho divino, consagró al sufragio como base del gobierno representativo, ciertamente con algunas limitaciones.

\section{LAS PRIMERAS ELECCIONES DE LOS ALCALDES Y DE LOS REGIDORES}

Uno de los aspectos más importantes es el mandato de restablecer una antigua y vital institución hispana: los municipios (ayuntamientos) y su libre elección popular.

En efecto, el art. 309 de la Constitución de Cádiz ordenaba que en todos los pueblos haya municipios compuestos de alcalde o alcaldes y regidores. La norma se refiere a "alcaldes", en plural, porque hasta 1856 cuando se dictó la Ley de Municipalidades se elegían por lo general dos. Uno civil y el otro del crimen.

Asimismo, la carta dispuso en su art. 312 que los alcaldes y regidores sean designados por elección de los pueblos. Esta novedosa disposición en un ambiente autocrático y virreinal, no acostumbrado a estos acontecimientos públicos y democráticos, desembocó en una explosión libertaria. Alcanzó ribetes de revolución, con efectos más profundos que los ocasionados por los enciclopedistas franceses. ${ }^{6}$ Valentín Paniagua, quien ha estudiado el tema con erudición, afirma que tuvo un gran impacto en un país carente de experiencia en gobiernos representativos y que daba lugar a un régimen popular desconocido ${ }^{7}$.

Cumpliendo su mandato, durante 1811 y 1812 en varias ciudades como Lima, Piura, Huánuco, Huancavelica, Lambayeque, Maynas, Cusco, Tacna,

\footnotetext{
Pareja Paz Soldán, José. Derecho constitucional peruano y la Constitución de 1979. 3ed. Lima, 1984, p. 25.

7 Paniagua, Valentín. Los orígenes del gobierno representativo en el Perú. Elecciones 1809-1826. Lima: PUC - Fondo de Cultura Económica, 2003, pp. 112 y ss.
} 
entre otras, se llevaron a cabo las primeras elecciones ediles. Se efectuaron de manera indirecta, por medio de representantes o electores, semejantes en algo a los actuales colegios electorales americanos.

El 9 de diciembre de 1812 le tocó a la capital y en acto solemne y público presidido por el virrey Abascal se eligieron a los dos primeros alcaldes constitucionales de la ciudad. Ganaron don Juan Bautista Lavalle y José María Sancho Dávila. Asimismo, se eligieron a 16 regidores y 2 procuradores síndicos.

\section{RAZONES DEL RESURGIMIENTO}

El cabildo hispano hunde sus raíces en la antigua comunidad romana denominada municipium. Al igual que ésta goza de autonomía frente a fuerzas externas. En España representaba el ancestral poder de los vecinos de una comarca, villa o pueblo; pero en 1594 había sido capturado por la aristocracia y el gobierno central a través de la libre compra y venta de los puestos, algunas veces a perpetuidad ${ }^{8}$.

El Alcalde de Zalamea, obra maestra de Calderón de la Barca durante el siglo de oro de inicios del s. XVII, muestra el liderazgo, decisión y orgullo de un alcalde de pueblo don Pedro Crespo contra un poderoso y noble oficial del rey. Crespo, afincado en su fuero municipal y como flamante alcalde, a pesar de que carece de jurisdicción sobre los militares, se atreve a juzgar y sancionar a la pena de muerte por garrote a un arrogante capitán real por su mal comportamiento con su hija9.

Las Cortes al no ser sino expresión genuina de la voluntad general de los pueblos hispanos que no reconocen autoridad en el falso rey José I (conocido popularmente como Pepe Botellas) impuesto por Napoleón, acuñan la doctrina que el poder radica en el pueblo y que éste se encuentra representado legítimamente por los municipios.

\section{LAS CONSTITUCIONES Y LA ELECCIÓN POPULAR DE LOS ALCALDES}

La constitución de 1823, la primera de la república peruana, reconoció en su art. 139 al pueblo como única fuente de poder local. Incluso fue más allá

\footnotetext{
8 PAREJA, O.C., p. 574.

9 Cfr. ANDÚJAR, Jorge. Sitio web: www.jorgeandujar.com
} 
detallando en el art. 140 los requisitos para ser alcalde o regidor: tener 25 años, ser natural del pueblo o 10 años de vecindad.

Todas las constituciones posteriores respetaron este sano principio. Las únicas que suprimieron a las municipalidades como expresión directa de la vida local fueron la vitalicia de 1826, de clara influencia bonapartista, y la carta de Huancayo de 1839. El carácter reaccionario, centralista, revanchista, y autoritario de esta última explica el retroceso.

Pero una cosa son los textos constitucionales, casi siempre líricos y hermosos; y otra distinta es la realidad histórica, siempre simple y dura. Comparemos ambos extremos en los textos de 1920 y 1933.

\section{LA CONSTITUCIÓN DE 1920 Y LAS ELECCIONES EDILES}

Esta carta tuvo una clara influencia del constitucionalismo social. Se advierte la impronta de la democrática Constitución alemana de Weimar de 1919 (que Hitler derogó para iniciar la locura del III Reich) y de la mexicana de 1917. A pesar de que su art. 141 copió literalmente el art. 118 de la Constitución de 1860, que ordenaba que la ley determinará la forma de las elecciones populares, durante los 13 años de su vigencia no se volvieron a convocar elecciones municipales.

No obstante que esta Constitución se hizo a imagen y semejanza del presidente Leguía, fue éste quien incumpliéndola abiertamente recomenzó a designar a dedo a las autoridades locales. Tanto a los alcaldes como a los regidores. Se les llamó eufemísticamente "Junta de Notables". El centralismo y la dependencia de los gobiernos locales se acentuaron enormemente, todo ello bajo las banderas de la descentralización que impulsaba esta carta.

Del mismo modo, a pesar de que la Constitución de 1933 (art.190) ${ }^{10}$ disponía expresamente que los alcaldes y regidores se elijan a través del sufragio directo y secreto, durante los primeros 30 años de su vigencia tampoco se convocaron a elecciones. Recién en 1963 el Arq. Belaúnde restableció el derecho de elegir a las autoridades locales. Desde allí y salvo el interregno del gobierno militar de 1968-1979, los comicios ediles y la voluntad popular se verifican escrupulosamente.

\footnotetext{
10 Art.190: «La ley fijará el número de miembros de cada Concejo departamental los que serán elegidos por sufragio directo y secreto...».
} 
No debe olvidarse que esta tradición democrática de elección popular de las autoridades ediles fue inaugurada y elevada al máximo rango constitucional por primera vez en la Constitución de Cádiz de 1812.

Asimismo, el art. 314 de la Constitución gaditana disponía que los alcaldes elegidos asuman el poder el primer día del año que inicia su período de gobierno, que entonces era anual. Este mandato se ha convertido ya en una tradición vigente en nuestros días, plasmada en la actualidad en el art. 34 de la Ley 26864 -Ley de Elecciones Municipales-. En efecto, todas las autoridades locales elegidas por el voto popular asumen sus cargos el primer día del año que se inicia su período municipal. Todo comenzó en Cádiz. 